\title{
Klappt die Gentherapie bei Cystischer Fibrose
} jetzt?

Fragestellungen: Ist eine Gentherapie mit kationischen Liposomen bei Cystischer Fibrose effizient und führt zu einer klinischen Besserung?

Hintergrund: Seit Entdeckung des Gens für Cystische Fibrose (CFTR) im Jahr 1989 wird an Möglichkeiten einer Gentherapie als Heilung für Menschen mit Cystischer Fibrose (CF) gearbeitet. Der Durchbruch blieb nach anfänglicher Euphorie aus, insbesondere die viralen Vektoren blieben ungeeignet. Schon lange wird an nicht viralen Vektoren geforscht. In dieser Studie wurden nun Plasmid-DNA-Liposomen-Komplexe, die in mehreren Phase-1- und 2a-Studien schon getestet wurden, auf ihre Effizienz bei CF-Patienten untersucht.

Patienten und Methoden: In die randomisierte, doppelblinde, placebokontrollierte Phase-2b-Studie wurden Patienten im Alter über 12 Jahre mit CF und

Alton EW, Armstrong DK, Ashby $D$ et al. Repeated nebulisation of non-viral CFTR gene therapy in patients with cystic fibrosis: a randomised, double-blind, placebo-controlled, phase $2 \mathrm{~b}$ trial. Lancet Respir Med. 2015 Sep;3(9):684-91. einer $\mathrm{FEV}_{1}$ von $50-90 \%$ pred. aufgenommen. Sie erhielten entweder $5 \mathrm{ml} \mathrm{0,9 \%} \mathrm{NaCl}$ inhalativ oder pGM169/GL67A, einen CFTR-Gen-Liposomen Komplex, alle 28 Tage über 12 Monate. Primärer Endpunkt war die Veränderung des $\mathrm{FEV}_{1}$. Sekundäre End-

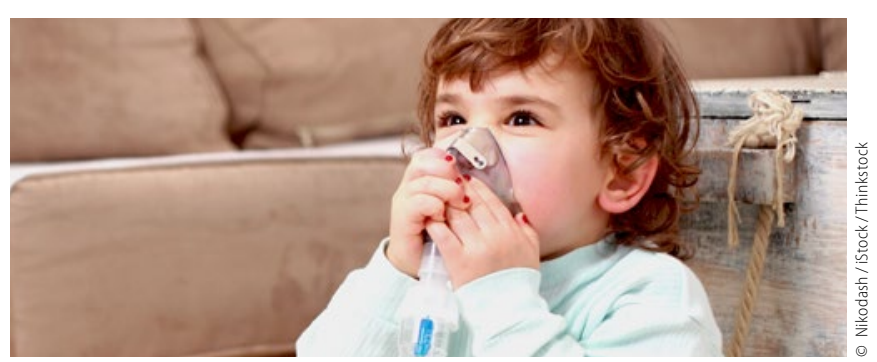

Bezüglich der Lungenfunktion könnte der Gentransfer für einen Teil der Patienten mit Cystischer Fibrose von Vorteil sein.

punkte waren die übrigen Parameter der Lungenfunktion, CTThorax und Lebensqualität.

62 Patienten in der Verum-Gruppe und 54 Patienten in der Placebo-Gruppe beendeten die Studie.

Ergebnisse: Die Verbesserungen der $\mathrm{FEV}_{1}$ in der Gruppe der Behandelten waren signifikant, aber sehr mäßig $(+3,7 \%)$ und nicht bei allen Behandelten nachweisbar, während es in der Placebo-Gruppe zu einem Abfall der $\mathrm{FEV}_{1}$ im Beobachtungsjahr kam (-4\%). Subgruppenanalysen ergaben, dass Patienten mit schlechterer Lungenfunktion eher eine Verbesserung des $\mathrm{FEV}_{1}$ entwickelten als Patienten mit einer besseren Lungenfunktion (nicht signifikant).

Die sekundären Parameter zeigten eine signifikante Verbesserung bei der FVC und bei in der CT nachgewiesenen Überblähung.

Unterschiede der beiden Gruppen bei den unerwünschten Nebeneffekten waren nicht nachweisbar.

\section{- Kommentar von Prof. Dr. med. Joachim Bargon}

\section{Eventuell zukünftige Option für ausgewählte Patienten}

Über 20 Jahre lang wird schon von verschiedenen Arbeitsgruppen an der Gentherapie für Cystische Fibrose geforscht und der Erfolg blieb bisher aus. Sämtliche viralen Vektoren erwiesen sich als wenig geeignet, um inhalativ in der Lunge als Dauertherapie eingesetzt zu werden und es blieben die nicht viralen Vektoren übrig.

In der vorliegenden Studie wurde erstmal gezeigt, dass bei wenig Nebenwirkungen eine Effizienz eines Gentransfers in die

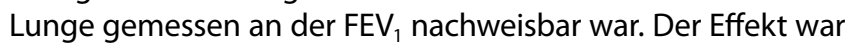
zwar signifikant, aber sehr moderat und bestand eher in einer Stabilisierung des Wertes gegenüber der Kontrollgruppe als in einer wirklichen Verbesserung. Immerhin waren aber - nach doch einigen Applikationen - keine wesentlichen Nebenwirkungen in Form von Inflammation oder Veränderungen der bakteriellen Besiedelung nachweisbar, sodass man davon ausgehen kann, dass eine Dauertherapie möglich sein könnte.

Ein Nachteil der Gentherapie ist sicher, dass dabei nur die Lunge behandelt wird, die anderen bei CF beteiligten Organe aber nicht - im Gegensatz zu den anderen Therapien wie Ivacaftor und Lumacaftor, die das defekte Protein in allen Orga- nen korrigieren oder dessen Effizienz potenzieren und die uns nun schon zur Verfügung stehen.

Vielleicht ist die Gentherapie in Zukunft eine Therapiemöglichkeit für die wenigen CF-Patienten, die auf die neuen oralen Medikamenten wegen ganz seltener Mutationen nicht ansprechen. Die meisten Patienten werden aber wohl eher von diesen Medikamenten profitieren, die uns schon jetzt oder in nächster Zukunft zur Verfügung stehen.

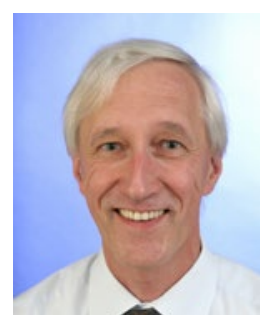

Prof. Dr. med. Joachim Bargon

St. Elisabeth Krankenhaus

Ginnheimer Straße 3

60487 Frankfurt

bargon@em.uni-frankfurt.de 